\title{
ARSITEKTUR RUMAH ADAT TRADISIONAL MBATANGU DI KAMPUNG RATENGGARO
}

\author{
Sopiah Bela Winne \\ Program Studi Arsitektur, Fakultas Teknik, Universitas Dwijendra \\ sovyacron@gmail.com \\ Frysa Wiriantari \\ Program Studi Arsitektur, Fakultas Teknik, Universitas Dwijendra \\ maheswarimolek@gmail.com
}

\begin{abstract}
Abstrak
Rumah tradisional Sumba tidak hanya memiliki makna yang timbul dari sistem kepercayaan, tetapi juga memiliki penyelesaian teknis yang mampu menyelesaikan permasalahan arsitektur yang timbul akibat bentuk dari bangunan tersebut. Rumah adat Mbatangu di kampung Ratenggaro yang dikenal dengan rumah menara, dibagi menjadi 3 bagian yaitu bagian bawah (kali kambunga), bagian tengah atau (uma dei), dan bagian atas (uma deta). Ketiga bagian ini memiliki sistem struktur yang saling terintegrasi dari pondasi hingga sistem struktur atapnya sehingga rumah adat ini dapat berdiri dengan bentuk yang unik dan menjadi bagian dari warisan kebudayaan masyarakat Sumba Barat Daya. Terutama arsitektur rumah adat Mbatangu yang berada di pesisir pantai, yang memiliki atap yang jauh lebih tinggi dibandingkan dengan rumah adat lainnya di daerah pegunungan.
\end{abstract}

Kata-kunci: Struktur, Rumah Adat, Rumah Menara, Ratenggaro

\begin{abstract}
Traditional Sumba houses not only have meaning arising from the belief system, but also have technical solutions that are able to solve architectural problems arising from the shape of the building. The Mbatangu traditional house in Ratenggaro village, known as the tower house, is divided into 3 parts, namely the lower part (kali kambunga), the middle part or (uma dei), and the upper part (uma deta). These three parts have an integrated structural system from the foundation to the roof structure system so that this traditional house can stand in a unique shape and become part of the cultural heritage of the people of Southwest Sumba. Especially the Mbatangu traditional house on the coast, which has a roof. which is much higher than other traditional houses in mountainous areas.
\end{abstract}

Keywords: Structure, Traditional House, Tower House, Ratenggaro

\section{PENDAHULUAN}

Rumah adat tradisional Sumba seperti halnya rumah tradisional di Indonesia lainnya pada umumnya ditemukan dalam bentuk kelompok (Mendra and Wiriantari, 2016), dimana rumah-rumah dalam kampung tersebut adalah kumpulan dari satu atau beberapa sub suku (kabihu), yang memiliki sub bahasa dan dialektika yang sama. Perkampungan Sumba tersebar dan terletak sesuai kondisi goegrafis dimana kampung tersebut berada, baik itu di tanah lapang atau padang, puncak bukit ataupun di lembah, di daerah pedalaman maupun di pesisir pantai. Dengan memiliki filosofi pembagian ruangan atas, ruangan tengah, dan ruangan bawah dengan memiliki fungsi masing-masing bagian .

Salah satu rumah adat Sumba yang akan dibahas adalah arsitektur rumah adat tradisional Mbatangu di Ratenggaro yang terletak di Kodi, Kabupaten Sumba Barat Daya yang dikenal dengan rumah menara adalah salah satu rumah adat yang menarik untuk dibahas. Rumah adat ini memiliki ciri khas dari bentuk atap yang tinggi dengan sistem struktur yang menggunakan material lokal dan tenaga manusia untuk membangunnya. Secara keseluruhan 
ditinjau dari segi aspek arsitekturalnya, semua rumah adat mempunyai keunikan dan daya tarik tersendiri untuk ditelaah dan dipelajari lebih lanjut serta dikembangkan dan diberikan informasi selengkap-lengkapnya kepada masyarakat dari segi bentuk bangunan, fungsi ruang hingga sistem strukturnya. Penelitian ini ditujukan untuk mengetahui keseluruhan sistem arsitektur rumah adat Mbatangu di daerah pesisir pantai (Ratenggaro) dari pondasi hingga atapnya serta penerapannya dengan material dan tenaga lokal. Metode penelitian yang digunakan adalah studi pustaka dan dokumentasi. Dari data-data yang ada, ditemukan bahwa sebagian besar struktur utama rumah adat ini menggunakan join sendi dan elemen stabilitas pada atap yang tinggi menggunakan bracing horisontal dan bracing vertikal. Diharapkan dari hasil penelitian ini, sistem struktur rumah adat di Ratenggaro dapat diterapkan pada arsitektur modern sehingga terjadi perkembangan arsitektur nusantara. Selain itu, hal ini juga diharapkan dapat menjadi pembelajaran bagi kaum muda dan menjadi kebanggaan bagi bangsa ini.

\section{Rumusan Masalah}

Dari penjelasan diatas dapat dirumuskan permasalahannya yaitu:

1. Bagaimana pengaruh bentuk dan ruang pada arsitektur rumah adat Mbatangu ?

2. Bagaimana pembagian ruang dan material apa yang digunakan?

3. Bagaimana penggunaan sistem struktur pada arsitektur rumah adat Mbatangu di Ratenggaro yang berada dipinggir pantai?

\section{Tujuan Penelitian}

Berdasarkan rumusan masalah diatas, maka tujuan penelitian yaitu:

1. Menemukan bagaimana pengaruh bentuk dan ruang pada arsitektur rumah adat Mbatangu.

2. Mengetahui bagian-bagian ruang, fungsi, dan material yang digunakan.

3. Mengidentifikasi penggunaan sistem struktur pada arsitektur rumah adat Mbatangu di Ratenggaro yang berada dipinggir pantai.

\section{Manfaat Penelitian}

1. Umum

Secara umum manfaat yang diharapkan dalam penelitian ini adalah memperkaya pengetahuan arsitektur tradisional di kepulauan Nusantara, khususnya pada hubungan antara bentuk, ruang, dan makna pada arsitektur rumah adat tradisional Mbatangu yang berada dipinggir pantai. Dengan pengetahuan akan bentuk, ruang, dan makna diharapkan dapat merekam kekhasan salah satu arsitektur tradisional di Nusantara yang sudah mulai hilang karena perkembangan jaman.

2. Khusus

a) Masyarakat Umum

Hasil penelitian ini diharapkan dapat menjadi rekaman kekhususan arsitektur tradisional Sumba. Selain itu dapat diharapkan menjadi panduan untuk mengenal identitas arsitektur rumah Sumba sehingga dapat digunakan untuk tempat wisata, panduan konservasi, dan sebagainya.

b) Kalangan Akademisi dan Perguruan Tinggi 
- Memperkaya ilmu pengetahuan dan dapat menjadi referensi bagi penelitian selanjutnya, baik tentang penelitian arsitektur tradisional rumah Sumba maupun arsitektur tradisional Indonesia lainnya. Serta dapat menjadi bahan untuk diskusi.

- Menjadi bahan ajar yang dapat dibagikan kepada mahasiswa/i untuk memperkaya pengetahuan tentang keragaman arsitektur tradisional di Indonesia.

- Menjadi rekaman ilmiah tentang arsitektur tradisional Indonesia, sehingga dapat melestarikan konsep dan pemikiran dalam arsitektur tradisional yang semakin menghilang seiring waktu.

\section{METODE PENELITIAN}

Penelitian ini bersifat deskriptif kualitatif dengan menggunakan data primer dan skunder, untuk mendeskripsikan pola hubungan yang terkait antara elemen fisik arsitektural dan tata spasial dengan latar belakang pembentuknya. Metode pengumpulan data yang digunakan dalam penelitian ini dilakukan dengan 3 cara yaitu:

1. Metode observasi

Metode ini dilakukan di lapangan dengan melakukan identifikasi di tempat penelitian, mengamati perilaku masyarakat, pemetaan kawasan dengan megambil gambar eksisting dan membuat sketsa tentang data yang diperlukan untuk penelitian ini.

2. Wawancara

Metode ini dilakukan dengan pertemuan antara dua orang atau lebih untuk bertukar informasi dan ide melalui tanya jawab, sehingga dapat dikonstruksikan makna dalam suatu topik tertentu.

3. Studi pustaka

Studi pustaka dilakukan dengan cara pengumpulan data berdasarkan sumber media cetak atau hasil karya yang tertulis dan telah dipublikasikan kepada masyarakat umum sehingga memiliki nilai ilmiah yang terjamin. Studi pustaka merupakan acuan terhadap data-data maupun landasan serta teori-teori yang sangat membantu dalam pengumpulan data yang tidak bisa didapatkan di lapangan. Studi pustaka dari literatur penelitan sebelumnya terkait topik penelitian untuk mendapatkan data pendukung yang lebih maksimal.

\section{HASIL DAN PEMBAHASAN}

Ratenggaro merupakan salah satu

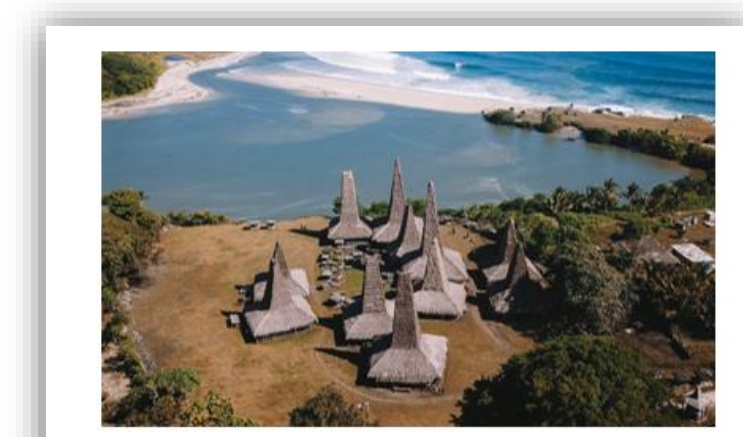

Gambar 1. Perkampungan Rumah Adat Tradisional Ratenggaro Sumber: https://wisatasumba.co.id/wp-content/uploads/2020/03/5.jpg

kampung adat di Sumba Barat Daya yang dikenal sebagai destinasi wisata alam dan budaya karena memiliki pantai yang indah dan kampung adat yang cantik. Kampung ini terletak di atas tebing pantai yang menghadap Samudra Hindia. Di bawahnya terdapat pertemuan aliran Sungai Waiha dan Samudra Hindia yang membentuk cekungan berpasir putih yang menawan. 
Meskipun belum dikembangkan menjadi destinasi wisata alam secara maksimal, sudah banyak turis dari mancanegara yang berkunjung ke pantai ini untuk mandi, berjemur, atau berselancar. Kampung Adat Ratenggaro terletak di bagian barat daya Pulau Sumba yang secara administratif merupakan bagian dari Desa Umbu Ngedo, Kecamatan Kodi Bangedo, Kabupaten Sumba Barat Daya. Berjarak sekitar 56 kilometer dari Tambolaka, Ibu Kota Kabupaten Sumba Barat Daya, kampung ini dapat ditempuh selama satu jam dengan beberapa jenis kendaraan, antara lain mobil sewaan, ojek sepeda motor, atau oto-sebutan untuk minibus yang menjadi modal transportasi umum di wilayah ini.

\section{Denah Kampung Ratenggaro}

Denah kampung seperti ditampilkan di atas menunjukkan orientasi setiap rumah yang tertuju pada bagian tengah, yaitu natara, yang dikitari oleh kubur batu para leluhur. Di area tengah kampung terdapat katoda atau batu pemujaan dan batu segel kampung. Rumah-rumah yang didirikan di dalam kompleks pagar batu di Kampung Adat Ratenggaro merupakan rumah-rumah bermenara atau rumah Mbatangu. Rumah Mbatangu dibangun berdasarkan kosmologi masyarakat Sumba yang membagi alam semesta ke dalam tiga lapisan. Lapisan pertama adalah loteng/menara rumah yang biasanya digunakan untuk meletakkan bendabenda keramat yang dianggap mewakili eksistensi marapu, lapisan kedua adalah balai-balai yang merupakan tempat untuk aktivitas manusia, dan lapisan ketiga adalah bagian bawah rumah yang biasanya digunakan untuk kandang hewan (Murni, 2007; Melalatoa, 1995). Tiga tingkatan dalam rumah tradisional Sumba tersebut melambangkan tiga tingkatan dalam alam kosmologi mereka, yaitu alam bawah (tana wawa) yang dianggap sebagai tempat tinggal makhluk halus, alam tengah/bumi (tana padua) sebagai tempat tinggal manusia dan makhluk hidup lainnya, dan alam atas (tana dita) sebagai tempat tinggal para dewa atau para marapu.

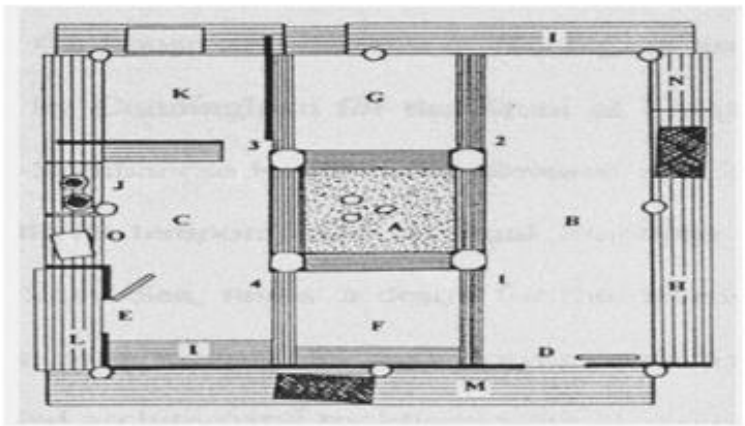

\section{Gambar 4. Denah Rumah Adat Tradisional Sumba \\ Sumber: Mross, 1955, p:8}

\section{Arsitektur Rumah Adat Tradisional Mbatangu di Kampung Ratenggaro}

\section{Denah}

Keterangan gambar:
A. Rapu atau perapian dengan 3 batu.
B. Penalunu, area pria.
C. Kerihanuangu, area wanita tempat mencuci peralatan memasak. 
D. Bina penalunu, pintu untuk kaum pria.

E. Bina kerihanuangu, pintu untuk kaum wanita.

F. Hadoka, bagian depan rumah formal.

G. Halibar, bagian belakang ruma informal, tempat membersihkan jenasah.

H. Hedang kabala mata, bale-bale tempat menerima tamu.

I. Pani deha, bale-bale dalam rumah.

J. Pajalu, kendi atau gerabah tempat air bersih.

K. Korung, ruang tidur (suami-istri).

L. Lenang erihanuangu, beranda atau teras untuk kaum wanita.

M. Lenang penalunu, beranda untuk kaum pria -formal.

N. Keripani, tempat untuk menunggu ketika Rato berdoa.

O. Hedang, tempat untuk menyimpan peralatan memasak.

\section{Pondasi}

Bagian bawah atau pondasi menggunakan tiang yang ditancapkan sedalam $50 \mathrm{~cm}$ ke dalam tanah yang kemudian diurug dengan batu cadas agar tidak mudah rubuh. Dengan kata lain, sistem pondasi yang digunakan pada rumah tradisional Sumba ini merupakan pondasi dengan sistem join sendi terbatas. Pondasi dengan join sendi ini, sebagai salah satu penyelesaian masalah struktur bangunan terhadap gempa. Hal ini hampir serupa dengan bangunan tradisional jineng pada Arsitektur Tradisional Bali (Wiriantari and Wijaatmaja, 2019).

\section{Lantai}

Pembalokan lantai rumah adat Sumba terdiri dari balok anak dan balok induk yang menggunakan material kayu. Pada bagian atasnya ditutup dengan susunan bambu/papan/balok kayu yang berfungsi sebagai penutup lantai. Ketinggian teras rumah $\pm 100 \mathrm{~cm}$ dari permukaan tanah datar, sehingga dibutuhkan beberapa anak tangga yang juga terbuat dari bambu untuk mencapai lantai. Ketinggian teras kedalam rumah $\pm 30 \mathrm{~cm}$. Pembalokan ditumpangkan pada kolom. Hubungan kolom dengan balok diikat dengan akar gantung. Kolom dan balok lantai terbuat dari kayu dolken.

\section{Kolom/Tiang}

Kolom yang terbesar dengan kualitas material yang paling baik pada rumah ini merupakan 4 buah kolom utama yang terletak pada bagian tengah rumah atau yang disebut dengan dapa koko pongga. 4 buah kolom utama ini berfungsi untuk menopang konsturksi utama atap menara dari rumah tersebut. Sedangkan kolom-kolom lain yang ukurannya lebih kecil dan kualitas materialnya lebih rendah dari 4 kolom utama disebut dengan kambaniru. Kolom-kolom tersebut berfungsi untuk menopang jurai dan balok-balok konstruksi lantai.

Kolom-kolom utama kemudian disatukan menggunakan balok kayu besar yang terbuat dari balok kayu kepala. Konstruktusi ini juga merupakan konstruksi lantai pada ruang marapu pada bagian atap atau atas bangunan. Join antar kolom dan balok kayu merupakan join sendi tanpa ikatan tetapi hanya coakan pada kolom dan balok diletakkan di atasnya. Setelah itu kemudian disusunlah kayu-kayu di atasnya sebagai pelat lantai untuk ruang marapu.

\section{Dinding}


Dinding rumah adat ini menggunakan bambu-bambu yang disusun secara horisontal yang kemudian dikakukan oleh kayu-kayu yang berdiri secara vertikal dengan jarak tertentu sehingga bidang dinding itu menjadi kuat dan tidak mudah melendut. Jenis sambungan dinding seperti ini menggunakan sistem lock, dimana bambubambu dikakukan/dikunci oleh kayu yang berdiri secara vertikal dengan cara diikat. Dari segi arsitektural, bambu yang disusun secara horisontal tersebut membuat rumah

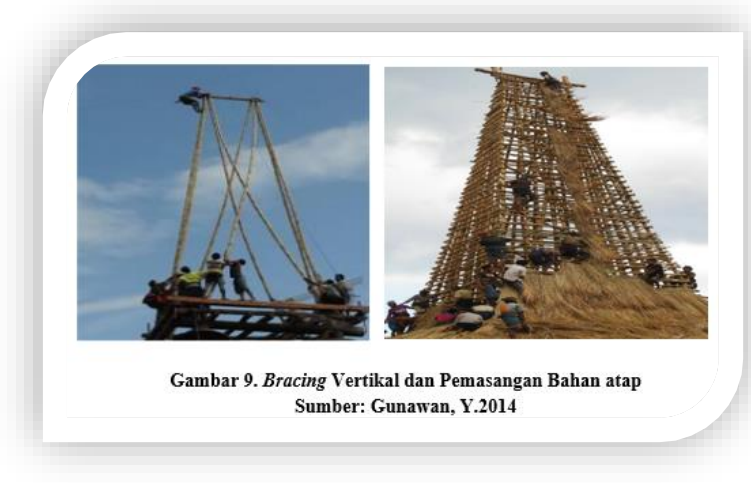
menara ini menjadi sejuk karena ada celah antar lubang bambu yang sehingga dapat terjadi pertukaran udara tanpa harus membuat sebuah bukaan yang lebar.

\section{Atap}

Kepercayaan masyarakat membagi rumah tradisionalnya menjadi 3 bagian yang masing-masing memiliki struktur yang terintegrasi. Atap pada rumah tradisional ini berbentuk limasan sederhana. Atap pada rumah rumah ini hanya menggunakan nok, jurai, gording dan sebagai struktur pembentuk atapnya tanpa menggunakan kuda-kuda maupun tiang untuk menahan ketinggian atap rumah tersebut. Bentuk atap yang tinggi menjadikan rumah ini tidak stabil akibat beban lateral yang diterimanya. Kestabilan pada atap rumah adat ini yang berada di sekitar pesisir pantai dicapai dengan penambahan bracing pada setiap gordingnya.

Peletakan bracing horisontal pada setiap gording diperlukan karena rumah Sumba suku Ratenggaro ini memiliki atap yang tinggi dan berada di sekitar pesisir pantai sehingga harus menahan beban angin yang lebih besar. Bracing ini digunakan untuk menjaga kestabilan atap dari beban angin yang cukup besar serta membantu penyaluran beban menuju ke elemen pengaku vertikal. Inilah yang membedakan struktur atap rumah adat Sumba Barat Daya di daerah pesisir pantai dengan rumah adat Sumba Barat Daya yang berada di daerah pegunungan.

Atap yang sangat tinggi tidak memungkin untuk distabilkan hanya dengan bracing vertikal karena akan menimbulkan lendutan pada atap. Gording pada atap rumah Sumba Barat Daya di sekitar pesisir pantai sebanyak 7 buah gording. Dimana setiap gording memiliki bracing horisontal sebagai elemen stabilitas. Setelah gording dan bracing dipasang, selanjutnya pemasangan reng dilanjutkan sebagai elemen konstruksi atapnya. Dan pemasangan yang terakhir adalah alang-alang sebagai penutup atap. Secara keseluruhan, sistem struktur dari rumah adat sumba barat ini menggunakan struktur rangka. Penyaluran sistem struktur rangka adalah penyaluran gaya melalui balok dan kolom dimana join antara kolom dan balok pada rumah ini adalah join sendi yang hanya diikat dengan menggunakan rotan dan akar gantung. Beban dari atap bangunan disalurkan menuju ke kolom dan balok hingga pondasi dan kemudian beban tersebut di salurkan menuju ke tanah. 


\section{PENUTUP}

\section{Kesimpulan}

Struktur rumah adat Mbatangu di Ratenggaro secara garis besar menggunakan struktur rangka pada bagian tegah dan atas rumah tersebut dimana rangka-rangka yang berupa kolom dan balok tersebut disambung dengan join sendi. Sama halnya dengan bagian bawah rumah menggunakan join sendi dimana kolom-kolom pada rumah tersebut hanya ditancapkan ke dalam tanah dan ditahan menggunakan batu cadas di sekelilingnya (join sendi) agar saat terjadi gerakan, bangunan ini tetap dapat sedikit bergerak tetapi tidak rubuh. Rumah adat Mbatangu di Ratenggaro juga sudah mengenal elemen stabilitas seperti yang terlihat pada atap rumah tersebut dimana terdapat bracing yang digunakan untuk memberi kestabilan pada atap rumah yang tergolong tinggi.

Pembangunan rumah adat ini sangat sederhana dengan menggunakan tenaga dan pikiran manusia tanpa menggunakan teori perhitungan. Masyarakat Sumba telah mampu mengatasi masalah-masalah struktur yang timbul hanya dengan sistem struktur dan materialmaterial yang tergolong sederhana. Penyelesaian struktur tersebut dapat dikembangkan dan dipelajari lebih lanjut agar sistem-sistem tersebut dapat diterapkan pada arsitektur modern sehingga kebudayaan Indonesia dapat dilestarikan dan berguna untuk perkembangan arsitektur nusantara serta dapat menjadi pembelajaran bagi anak-anak kaum muda sekarang bahwa tidak semua material dan bangunan-bangunan lokal memiliki kualitas yang buruk. Rumah adat di Indonesia juga telah dikagumi dan menjadi sorotan bagi bangsa-bangsa lain sehingga kita dapat bangga menjadi bangsa Indonesia.

\section{Saran}

Penulis memberikan uraian yang diberikan pada penulis sendiri, bagi pembaca dan masyarakat yaitu:

1) Diharapkan bagi penulis untuk menambah wawasan dalam pengertian arsitektur rumah adat Mbatangu di kampung Ratenggaro.

2) Diharapkan bagi pembaca, untuk menambah wawasan dan pengetauan tentang struktur arsitektur rumah adat Mbatangu di kampung Ratenggaro.

3) Diharapkan bagi masyarakat untuk menjaga arsitektur rumah adat tradisional Mbatangu di Ratenggaro, sebagai warisan dari nenek moyang untuk diperkenalkan kepada anak cucu, dan menjadi tempat parawisata budaya.

\section{DAFTAR PUSTAKA}

Hariyanto, dkk. (2012). Hubungan Ruang, Bentuk, dan Makna pada Arsitektur Tradisional Sumba Barat. Laporan_Penilitian NO._01/LPPM/UKP/2012, Universitas Kristen Petra.

Melalatoa. (1995). Proyek Pengkajian dan Pembinaan Nilai-Nilai Budaya.

Mendra, I. W. and Wiriantari, F. (2016) 'Perubahan Spasial Permukiman Tradisional di Desa Adat Tenganan Pegringsingan Bali', Jurnal Anala, 1(15), pp. 73-97. Available at: https://scholar.google.com/citations.

Murni Winarsih. (2007). Intervensi Dini Bagi Anak Tunarungu Dalam Pemerolahan Bahasa. Departemen Pendidikan dan Kebudayaan. Direktorat Jenderal Pendidikan Tinggi. Direktorat Ketenagaan. 
Nurdiah, Esti Asih dan Agus Dwi Hariyanto. "Struktur Rangka Atap Rumah Tradisional Sumba". Makalah dalam Seminar Nasional "Reinterpretasi Identitas Arsitektur Nusantara", Bali-2013, ISBN No. 978-602-7776-68-5.

Purwati, Wiwik. (2013). Identifikasi Pola Peruangan Rumah Adat di Laura Sumba Barat Daya. Laporan Penilitian._Lembaga Penilitian dan Pengabdian Masyarakat, UAJY.

Wiriantari, F. and Wijaatmaja, A. B. M. (2019) 'PERUBAHAN BENTUK, FUNGSI DAN STRUKTUR JINENG DALAM ARSITEKTUR TRADISIONAL BALI', in Suaradnyana, K. (ed.) Seminar Nasional Inovasi dalam Penelitian Sains, Teknologi dan Humaniora. Denpasar: Dwijendra University, pp. 38-49.

Windadari, dkk, (2006)' Sistem Struktur Rumah Adat Barat Ratenggaro_Temu Ilmiah

http://warisanbudayaindonesiaonline.com/rumah-adat-sumba.05/05/201

https://eproceeding.undwi.ac.id/index.php/semarayana/article261Arsitektur_Rumah_adat_Tr adisional_Sumba. 09/08/2020

https://id.m.wikipedia.org/wiki/Rumah_Adat_Sumba. 09/08/2020.

amazingsumba.wordpress.com.(2013).Kampung Ratenggaro, Sumba Barat Daya [Online]. $21 / 08 / 2020$

https://temuilmiah.iplbi.or.id/wp-content/uploads/2015/01/TI2014-C-p007-012-SistemStruktur-Rumah-Adat-Barat-Rattenggaro.pdf 21/08/2020 